\title{
Student's Reading of Thematic Maps from Czech School World Atlas - an Eye-tracking Study
}

\author{
Marketa Beitlova $^{\mathrm{a}, *}$, Stanislav Popelka ${ }^{\text {a, }}$ Vit Vozenilek ${ }^{\text {a }}$ \\ a Department of Geoinformatics, Palacký University Olomouc, Czech Republic, Marketa Beitlova - marketa.beitlova@upol.cz, \\ Stanislav Popelka - stanislav.popelka@upol.cz,VitVozenilek - vit.vozenilek@upol.cz
}

* Corresponding author

Keywords: cartography, atlases, eye-tracking, evaluation, education

\begin{abstract}
:
According to the cartographic communication models, the map is intended as a product which helps people to understand the world. Usually, the first systematic cartographic product which pupils and students met in their lives is a school world atlas. In the Czech Republic, these atlases are used in almost every geography lesson. Thus, school atlases should be understandable, well-arranged, intelligible and easy to use by students. However, almost no empirical studies focused on this type of product exist.

This presentation summarizes the results of the experiment, where the task was to find some object on the thematic map. The research aimed on two main issues: if the students are able to read thematic maps from school world atlas (Q1) and if the used cartographic visualization methods are properly selected (Q2).

For finding answers to these research questions, the eye-tracking study conducted on 30 grammar school students was performed. This study contained ten tasks on the thematic world maps from the Czech school world atlas. Depending on the type of information displayed, visualization method and legend style, the tasks were formulated for each map. Eyemovement data were recorded using low-cost GazePoint eye-tracker with sampling frequency of $60 \mathrm{~Hz}$. The first research question - if students can work with the thematic maps from school world atlas - was analysed using the correctness of answers and Trial Duration - the metric that shows how much time respondents needed to find the answer. For answering the second research question - if the cartographic methods used in the atlas are understandable - qualitative data visualization methods were used.
\end{abstract}

At the beginning of the recorded data analysis, the correctness of answers and trial duration was ïnvestigated. These results helped us to find out, how the students were able to read the maps, if their answers were correct and how much time they needed for task solving. The results showed that generally, the students could read thematic maps (Q1). The most problematic task was the one where students had to estimate the pie-chart value according to the logarithmic scale.

In the next step, the behaviour of students while solving each task was qualitatively described and problematic cartographic visualization methods were identified (Q2). For example, in some cases, used symbols were difficult to distinguish. The most serious problems were in the task, where students had to estimate the value of the bar chart. The scale of the legend was designed so that one millimetre of the bar corresponds to 50 million USD of export volume. This cartographic method was hard to understand for the students.

The conducted eye-tracking study pointed out to maps where the cartographic methods were misused and caused problems to the students. The results might help the cartographers and map publishers who can modify the maps to be more understandable for the readers.

\section{Acknowledgements}

The research was supported by the project of the NAKI II programme no. DG20P02OVV029. 